\title{
Small Intestine in Psoriasis
}

\author{
SAM SHUSTER,* M.B., PH.D., M.R.C.P.; A. J. WATSON, $\dagger$ M.D., M.C.PATH. ; JANET MARKS, † B.A., B.M., M.R.C.P.
}

We have shown that patients may develop an enteropathy as a result of extensive skin disease (Shuster and Marks, 1965). Some of the patients whose cases we described had psoriasis, and so it became important to find out whether bowel abnormalities were a common feature of this disease.

\section{Patients and Methods}

Twenty-three female and 19 male patients were studied. Their ages ranged from 15 to 72 years. The total length of history of psoriasis ranged from 3 weeks to 50 years, and the duration of the most recent episode from 1 week to 20 years. All patients had been admitted to hospital for treatment and were studied consecutively, apart from a few who declined the investigation. None of the patients had a history of diarrhoea or bulky stools. The extent of the rash was assessed visually on admission.

Faecal fat excretion was measured in 26 patients. With the patient on a normal ward diet, which was estimated to contain about $100 \mathrm{~g}$. of fat a day, faeces were collected for five consecutive days. The mean daily faecal fat excretion was measured by the method of Van de Kamer, ten Bokkel Huinink, and Weyers (1949), a mean fat excretion of more than $5 \mathrm{~g}$. being regarded as abnormal.

$\mathrm{D}-X y$ lose absorption was measured in 10 patients. After an overnight fast $25 \mathrm{~g}$. of $\mathrm{D}$-xylose was given and urine was collected over the next five hours. In some cases a sample of blood was taken two hours after the dose of sugar. Xylose in the blood and urine was measured by the method of Roe and Rice (1948), excretion of less than $4.1 \mathrm{~g}$. of xylose in the urine in five hours being regarded as abnormal (Fourman, 1948).

\section{Mucosal Biopsy of Small Intestine}

With the use of a Crosby capsule (Crosby and Kugler, 1957) a peroral biopsy specimen of small-intestinal mucosa was obtained from 26 patients, including 12 who had had a faecal fat examination. The position of the capsule was first verified radiologically; in most cases it was in the proximal loop of the jejunum, but occasionally it was in the fourth part of the duodenum. The specimen was retrieved with the minimum of delay and was transported to the laboratory in ice-cold buffered sucrose solution $(0.22 \mathrm{M})$. With the aid of a stereoscopic dissecting microscope the specimen was then spread out, mucosal surface upwards, on a flat piece of cellulose sponge and divided in two. One piece was immediately frozen by dropping it in liquid nitrogen and was stored at $-70^{\circ} \mathrm{C}$. in a small airtight container for subsequent histochemical examination. The interval between the firing of the capsule and the quenching of the selected part of the biopsy specimen in liquid nitrogen ranged from 7 to 10 minutes.

The remaining part of the specimen was fixed in $10 \%$ formolcalcium for at least 24 hours. Mucus and intestinal debris

\footnotetext{
* Professor of Dermatology, Royal Victoria Infirmary, Newcastle upon Tyne 1 .

t Senior Lecturer in Pathology, Royal Victoria Infirmary, Newcastle

upon Tyne 1 .
₹ Lecturer in Dermatology, Royal Victoria Infirmary, Newcastle upon Tyne 1 .
}

were then gently removed from the mucosal surface by means of a soft brush, and the mucosa was examined through the dissecting microscope and photographed. After processing through to paraffin wax, histological sections were cut at a thickness of 5 microns. Care was taken to ensure that the sections were cut in a plane perpendicular to the muscularis mucosae in order to obtain a true measure of villous height in relation to the crypt depth.

Correct orientation in the paraffin block was facilitated by the method of fixation, which prevented the specimen from becoming curled or folded. Finally, the sections were stained by various methods, including haematoxylin and eosin, and the periodic-acid-Schiff method.

\section{Dissecting Microscope Appearances}

We have followed the terminology of Booth, Stewart, Holmes, and Brackenbury (1962). Finger-shaped villi are self-explanatory. Leaves are a heterogeneous group of villi which are broadened in one cross-sectional diameter. Straight mucosal ridges appear to be an exaggeration of the leaf-shaped forms and the dividing line between them is arbitrary. We define ridges as having a ratio of width to height of greater than three to one. Ridges which pursue a winding course are described as convoluted. A mucosa from which all villi and ridges have disappeared is conventionally described as flat.

\section{Histological Appearances}

Partial villous atrophy (Doniach and Shiner, 1957) is the histological counterpart of a convoluted mucosa as seen by the dissecting microscope (Booth et al., 1962). In normal jejunal mucosa the villi are at least twice as tall as the crypts are deep (Hourihane, 1966), and we consider partial villous atrophy to be present when there is shortening of the villi, with or without lengthening of the crypts. This is usually accompanied by an increased number of plasma cells and eosinophils in the lamina propria, and sometimes the surface epithelium is infiltrated by lymphocytes. Occasionally there are foci of irregularity of the surface epithelium similar to that found in subtotal villous atrophy.

\section{Classification}

Our classification is based on the stereomicroscopical and histological appearances and is summarized as follows:

(1) Normal: Fingers and narrow leaves.

(2) Equivocal: Broad leaves and short straight ridges. May show increase of chronic inflammatory cells in lamina propria.

(3) Abnormal: (a) Convoluted. Predominance of angulated ridges. Surface epithelium focally abnormal, increased inflammatory cells, and partial villous atrophy. (b) Flat. No villi, but mosaic pattern and prominent crypt openings. Surface epithelium abnormal, with increased inflammatory cells. 


\section{Histochemical Studies}

Frozen sections from the unfixed material were cut at a thickness of 10 microns in a cryostat cabinet maintained at a temperature of $-20^{\circ} \mathrm{C}$. Leucine aninopeptidase was demonstrated by the method of Nachlas, Crawford, and Seligman (1957) L-leucyl-4-methoxy- $\beta$-napthylamide being used as substrate (Rosenblatt, Nachlas, and Seligman, 1958). Nonspecific alkaline phosphatase was demonstrated after the method of Burstone (1958a) with naphthol-ASMX-phosphate as substrate. Adenosine triphosphatase was demonstrated after the method of Padykula and Herman (1955) with $\mathrm{CaCl}_{2}$ in the incubating medium at a concentration of $0.227 \mathrm{M}$. Nonspecific acid phosphatase was demonstrated by the method of Burstone (1958b) with naphthol-ASMX-phosphate as the substrate. Succinate dehydrogenase was demonstrated after the method of Nachlas, Tsou, de Souza, Cheng, and Seligman (1957). Glucose-6-phosphate deh-jdrogenase was demonstrated by the method of Hess, Scarpelli, and Pearse (1958) with the use of MTT tetrazolium salt. Non-specific esterase was demonstrated by the method of Novikoff and Goldfischer (1961).

\section{Results}

Fig. 1 shows that 15 of the 26 patients examined excreted more than $5 \mathrm{~g}$. of fat a day in their faeces. Both the incidence and the degree of steatorrhoea were clearly related to the extent of the psoriasis. There was no apparent relation to age, sex, and total duration of psoriasis, or to the duration of the most recent episode. D-Xylose excretion was abnormal in 4 of the

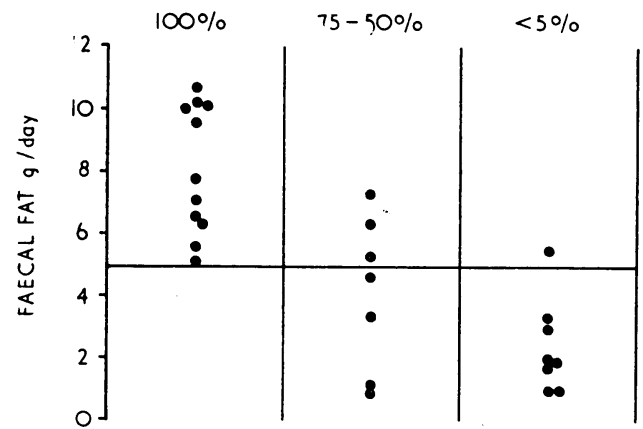

FIG. 1.- Relation between faecal fat excretion and proportion of skin surface affected by psoriasis.

10 patients in whom it was measured, and three of these abnormal results were in patients with steatorrhoea (Table I).

The stereomicroscopical appearances of the small-intestinal mucosa are summarized in Table II. In 12 patients ( $46 \%$ ) the mucosa was frankly abnormal with a convoluted appearance (Fig. 2) and histologically showed partial villous atrophy. Most

TABLE I.-Faecal Fat Excretion and Urinary D-Xylose Excretion in Patients with Psoriasis

\begin{tabular}{|c|c|c|c|}
\hline Case No. & $\begin{array}{l}\text { Faecal Fat } \\
\text { (g./day) }\end{array}$ & $\begin{array}{c}\text { Plasma D-Xylose } \\
\text { (mg./100 ml.) }\end{array}$ & $\begin{array}{l}\text { Urinary } \mathrm{D}-\mathrm{Xylose} \\
\quad(\mathrm{g} .15 \text { hours })\end{array}$ \\
\hline $\begin{array}{r}1 \\
2 \\
3 \\
4 \\
5 \\
6 \\
7 \\
8 \\
9 \\
10\end{array}$ & $\begin{array}{r}3.0 \\
10.1 \\
7.8 \\
10.6 \\
5.4 \\
6.4 \\
1.0 \\
9.6 \\
1.9\end{array}$ & $\begin{array}{l}39 \\
27 \\
11 \cdot 8 \\
43 \\
41 \\
= \\
= \\
=\end{array}$ & $\begin{array}{l}0 \cdot 3 \\
1.7 \\
2 \cdot 2 \\
3 \cdot 8 \\
4 \cdot 2 \\
5 \cdot 2 \\
5 \cdot 6 \\
5 \cdot 7 \\
5 \cdot 8 \\
7 \cdot 1\end{array}$ \\
\hline
\end{tabular}

TABle II.-Mucosal Abnormalities in 26 Patients with Psoriasis

\begin{tabular}{c|c|c|c}
\hline \multirow{2}{*}{ Normal } & Equivocal & \multicolumn{2}{|c}{ Abnormal } \\
\cline { 2 - 3 } & 4 & Convoluted & Flat \\
\hline 10 & 12 & 0
\end{tabular}

of the abnormal mucosae were found in the younger age group ; none of the patients had a flat mucosa. Unlike the steatorrhoea, the degree of mucosal abnormality was not apparently related to the extent of the psoriasis (Fig. 3).

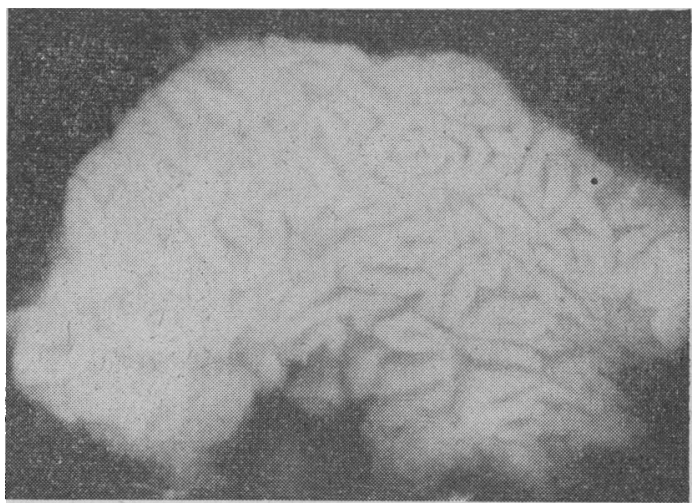

FIG. 2.-Dissecting microscope $(\times 12)$ appearance of convoluted jejunal mucosa from patient with psoriasis.

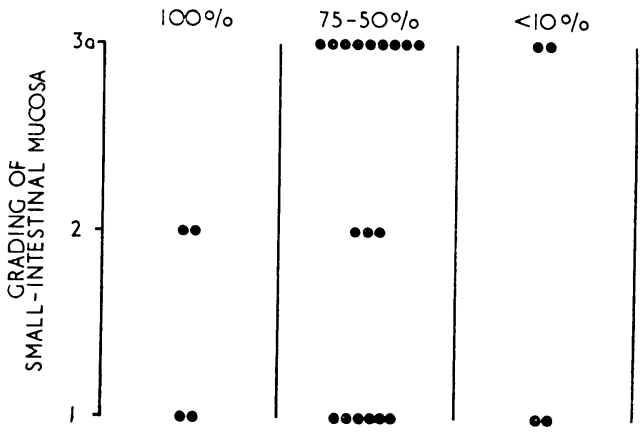

FIG. 3.-To show lack of correlation between mucosal involvement and proportion of skin surface affected by psoriasis.

An abnormality was noted in 12 of the 24 patients whose mucosal biopsies were examined for enzyme activity. This abnormality occurred mainly in patients with a convoluted mucosa. The columnar cells of the surface epithelium covering the free ends of the villi showed loss or inhibition of three membrane enzymes associated with the brush borders of the cellsthat is, leucine aminopeptidase, non-specific alkaline phosphatase, and adenosine triphosphatase (Fig. 4). The activity of these enzymes was normal in the brush border other than at the free ends of the villi. Furthermore, the affected cells showed no abnormality in the activity or distribution of the other enzymes studied. In one patient a second biopsy taken six weeks after the first again showed the abnormality. The affected cells showed no unusual features in haematoxylin-andeosin-stained paraffin sections, and the brush borders gave their usual deep staining reaction with the periodic-acid-Schiff method.

\section{Discussion}

Steatorrhoea is common in patients with psoriasis, and this disease and eczema are the main known causes of dermatogenic enteropathy (Shuster and Marks, 1965 ; Watson, Marks, and Shuster, 1967 ; Shuster, 1967a, 1967b). In the present study a convoluted mucosa, together with a histological appearance of partial villous atrophy, was found in 12 out of 26 patients with psoriasis. Though a convoluted mucosa has been found in apparently normal Asians living in India (Baker, Ignatius, Mathan, Vaish, and Chacko, 1962) and Singapore (England and O'Brien, 1966), it was not found in Europeans living in the same area. In a recent study of malabsorption in Scotland (Girdwood, Williams, McManus, Dellipiani, Delamore, and 
Kershaw, 1966) none of the 52 control subjects showed a ridged or convoluted jejunal mucosa. It appears, therefore, that our finding of a convoluted mucosa in $46 \%$ of our patients with psoriasis is significant. Though none of our patients had a flat mucosa with subtotal villous atrophy we would not wish to exclude the possibility that this may occur.

The steatorrhoea is closely related to the extent of skin involvement (Fig. 1), whereas the mucosal abnormality is not so related (Fig. 3). It is likely, therefore, that there is no relation between degree of steatorrhoea and severity of mucosal abnormality, though our present data on this point are incomplete.

The enteropathy of psoriasis is characterized, therefore, by steatorrhoea with partial villous atrophy or an apparently normal mucosa. In this respect psoriatic enteropathy resembles tropical sprue rather than coeliac disease (England and O'Brien, 1966), as do other forms of dermatogenic enteropathy (Shuster, 1967a, 1967b ; Watson et al., 1967).

Many of the biopsy specimens were found to have lost activity of membrane enzymes in the brush borders of the absorptive cells over the free ends of the villi. The possibility of an artifact cannot be completely excluded, though we have been unable to incriminate any variation in our laboratory procedures. In one patient two biopsies were taken at an interval of several weeks and the abnormality was present in both. The site of the abnormality raises the possibility that it has resulted from the action of the intestinal contents on the cell surface. Alternatively there may be some intrinsic abnormality of the epithelium. Though this histochemical abnormality has been

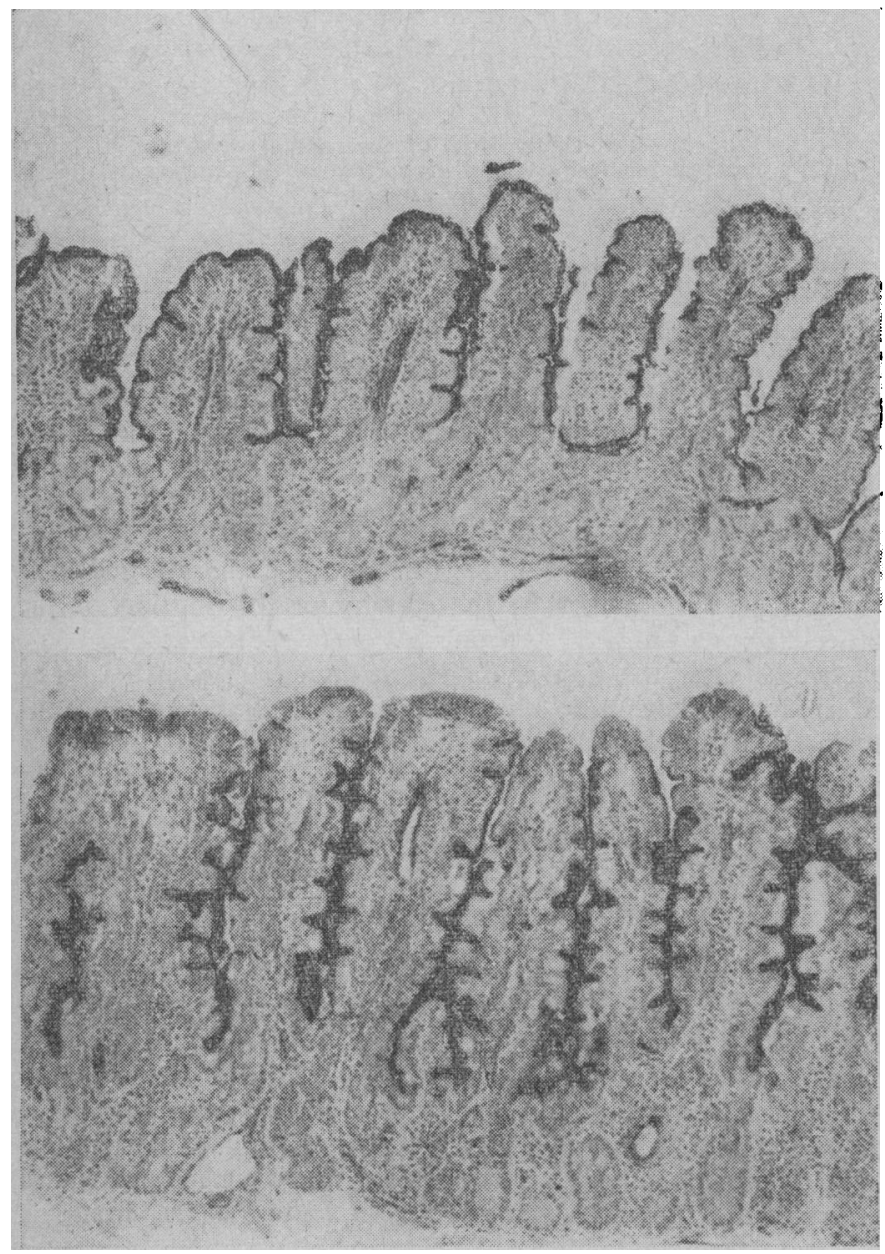

FIG. 4.-Microscopical appearances $(\times 63)$ of jejunal mucosa from two patients with psoriasis. Above: normal distribution of adenosine tri phosphatase activity in surface epithelium of villi. Below: loss of adenosine triphosphatase activity in surface epithelium over free ends of villi. found most commonly in patients with psoriasis, it has also been seen in a few patients with eczema, pemphigoid, and dermatitis herpetiformis (unpublished observations), and further investigations are in progress.

As with the other forms of dermatogenic enteropathy the immediate cause of the intestinal disorder of psoriasis is speculative (Shuster, 1967a, 1967b). Since the incidence and degree of the steatorrhoea are related to the extent of the skin disease, and since it regresses when the rash is treated topically (Shuster and Marks, 1965), the steatorrhoea is clearly secondary to the skin disease. We do not yet know whether the jejunal mucosa likewise reverts to normal after treatment.

The true incidence and severity of psoriatic enteropathy are unknown; the findings in the present study may reflect the severity of the rash in patients referred to our unit, and much further work will need to be done to define the practical importance of psoriatic and other dermatogenic enteropathies.

\section{Summary}

Small-intestinal structure and function were investigated in patients with psoriasis. Faecal fat excretion was measured in 26 and $\mathrm{D}$-xylose absorption in 10 ; jejunal biopsy appearances were studied in 26 . The incidence and degree of steatorrhoea were related to the extent of skin involvement. A convoluted appearance was found in $46 \%$ of the jejunal mucosae examined, and a number of these showed a loss of enzyme activity in the brush border of the absorptive cells at the free ends of the villi.

We are grateful to our colleagues at the Royal Victoria Infirmary and the North-east Region for referring patients to us. We are also grateful to Professor A. L. Latner, in whose department the fat and xylose estimations were carried out. We wish to thank Mr. J. R. Maclennan and Mr. J. A. Stewart for valuable technical assistance.

The work was supported by a grant from the Medical Research Council, which we are happy to acknowledge.

\section{REFERENCES}

Baker S. J Ignatius, M., Mathan, V. I., Vaish, S. K., and Chacko, C. C. (1962). In Intestinal Biopsy, Ciba Foundation Study Group No. 14, edited by G. E. W. Wolstenholme and M. P. Cameron. London.

Booth, C. C., Stewart, J. S., Holmes, R., and Brackenbury, W. (1962). Ibid.

Burstone, M. S. (1958a). 7. Histochem. Cytochem., 6, 87.

Burst $1958 \mathrm{~b}$. $\mathrm{Nat}$ Cancer Inst. 21, 523.

Crosby, W. H., and Kugler, H. W. (1957). Amer. 7. dig. Dis., 2, 236.

D. (1957). Gastroenterology, 33, 71 .

England, N. W. J., and O'Brien, W. (1966). Gut, 7, 128

Fourman, L. P. R (1948). Clin. Sci., 6, 289.

Girdwood, R. H., Williams, A. W., McManus, J. P. A., Dellipiani, A. W. Delamore, I. W., and Kershaw, P. W. (1966). Scot. med. F., 11, 343.

Hess, R., Scarpelli, D. G., and Pearse, A. G. E. (1958). Nature (Lond.), 181,1531 .

Holt, S. J. (1958). In General Cytochemical Methods, edited by J. F. Danielli, vol. 1 , p. 375. New York and London.

H. (1966). In Recent Advances in Pathology, 8th ed. edited by C. V. Harrison, p. 320. London.

Nachlas, M. M., Crawford, D. T., and Seligman, A. M. (1957). f. Histochem. Cytochem., 5, 264.

Tsou, K.-C., de Souza, E., Cheng, C.-S., and Seligman, A. M. (1957). Ibid., 5, 420.

Novikoff, A. B., and Goldfischer, S. (1961). Proc. nat. Acad. Sci. (Wash.), 47, 802

Padykula, H. A., and Herman, E. (1955). f. Histochem., 3, 161.

Padykula, H. A., and E. W. (1948). F. biol. Chem., 173, 507.

Roe, J. H., and Rice, Nachlas, M. M., and Seligman, A. M. (1958). F. Amer. chem. Soc., 80, 2463.

Symposium on Advanced Medicine, edited by A. Dawson. Royal College of Physicians London. In press. (1967b). Lancet, 1, 907.

- Ibid., 1, 1367.

Van de Kamer, J. H., ten Bokkel Huinink, H., and Weyers, H. A. (1949). 7. biol. Chem., 177, 347.

patson, A. J., Marks, J. M., and Shuster, S. (1967). Unpublished observations. 